\title{
EN TORNO AL CASTICISMO DE PEDRO: EL PRINCIPIO Y EL FIN DE TIEMPO DE SILENCIO
}

Por

CARLOS FEAL

State University of New York at Buffalo

Como el título indica, me propongo comentar el principio y el final de Tiempo de silencio de Luis Martín-Santos. Esos dos momentos, cruciales en toda novela, son en este caso especialmente importantes para dilucidar el carácter del protagonista, Pedro, las relaciones que mantiene con el autor y, en última instancia, la significación de la obra. Ocasionales referencias a otros pasajes me serán necesarias; pero, en la mayor parte de mi trabajo, me mantendré dentro de los límites señalados.

La novela se inicia con un monólogo de Pedro, cuyas investigaciones sobre el cáncer se ven interrumpidas por la falta de ratones con que llevar a cabo los experimentos. Varios críticos han interpretado el cáncer como un símbolo de los males de la sociedad española. ${ }^{1}$ Pero el problema de España no se plantea únicamente en términos simbólicos; abundan las referencias directas al mismo. Ya en ese primer monólogo, Pedro manifiesta su preocupación: "Pueblo pobre, pueblo pobre. ¿Quién podrá nunca aspirar otra vez al galardón nórdico, a la sonrisa del rey alto, a la dignificación, al buen pasar del sabio que en la península seca, espera que fructifiquen los cerebros y los ríos?"2 La pobreza es doblemente responsable del atraso científico de España, que impedirá a Pedro, o a quienquiera que sea, alcanzar el Premio Nobel. Pues tal atraso se debe a la vez a falta de medios materiales y a insuficiencia cerebral producida por el desnutrimiento. Así continúan las reflexiones de Pedro: “¿Cómo podremos nunca, si además de ser más torpes, con el ángulo facial estrecho del hombre peninsular, con el peso cerebral disminuido por la dieta monótona por las muelas, fabes, agarbanzadas leguminosas y carencia de prótidos? Sólo tocino, sólo tocino y gachas" (p. 8).

\footnotetext{
1 Véase José Ortega, "La sociedad española contemporánea en Tiempo de silencio de MartínSantos", Symposium, 22 (1968), 256; Juan Carlos Curutchet, "Luis Martín-Santos: el fundador", en Cuatro ensayos sobre la nueva novela española (Montevideo: Alfa, 1973), p. 35.

${ }^{2}$ Luis Martín-Santos, Tiempo de silencio, $6^{\text {a }}$ ed., (Barcelona: Seix Barral, 1969), p. 7. Todas la citas son de esta edición. Las indicaciones de página se incluyen, a continuación, en el texto.
} 
Es, sin embargo, importante advertir que el pesimismo de Pedro viene contrarrestado por la presencia de fantasías con que llenar el hueco dejado por la ciencia. En primer lugar está el retrato de Ramón y Cajal, el Premio Nobel español, elevado por Pedro a la categoría de auténtico mito: "El retrato del hombre de la barba, frente a mí, que lo vio todo y que libró al pueblo ibero de su inferioridad nativa ante la ciencia" (p. 7). De aquí pasa el protagonista a contemplarse, al unísono con su pueblo, empeñado en prodigiosa tarea: "El terebrante husmead or de la realidad viva con ceñido escalpelo que penetra en lo que se agita y descubre allí algo que nunca vieron ojos no ibéricos. Como si fuera una lidia. Como si de cobaya a toro nada hubiera, como si todavía nosotros a pesar de la desesperación, a pesar de los créditos"(pp.7-8). Ante la dificultad el español se crece, como el torero ante el toro; su supuesta inferioridad se transforma en superioridad absoluta, patente en su poder ver, aun con rudimentarios microscopios, lo que "nunca vieron ojos no ibéricos". Digno descendiente, en efecto, del suprahumano "hombre de la barba", Ramón y Cajal, el hombre "que lo vio todo".

La ironía existente en estas páginas iniciales no parece dudosa. A través de las fantasías de Pedro percibimos el tono de burla del autor, distanciado de su personaje. Este último habría interiorizado los prejuicios de su pueblo, como muestra su exaltación mítica de Cajal y del torero, el ídolo de las masas, con quien Pedro se confunde, a la vez adorador y adorado. Pero la circunstancia de que Pedro sea un hombre culto, inteligente, cuyas id eas en otros casos no es posible distinguir de las del autor, mueve a pensar en lo difícil que resulta para cualquiera liberarse de opiniones y estimaciones colectivas.

Pongamos otro ejemplo, para completar los anteriores. La falta de ratas, procedentes de los Estados Unidos, traslada a este país la imaginación de Pedro. La prosperidad norteamericana, a los ojos del pobre españolito, produce las imágenes de los "laboratorios traslúcidos de paredes brillantes de vidrio, con aire acondicionado ex profeso para la mejor vida ratonil" (p.9) y de las "rubias mideluésticas mozas con proteína abundante durante el período de gestación de sus madres de origen sueco o sajón y en la posterior lactancia y escolaridad. Aunque hermosas, insípidas pero nunca oligofrénicas, con correcta emigración de neuroblastos hasta su asentamiento ordenado en torno al cerebro electrónico de carne" (p. 9). Como se ve, la opulenta norteamérica no sale muy bien parada de esta visión. La oligofrenia española tiene como contrapartida la insipidez estadounidense, y cómo comparar la fabulosa figura del torero con la de unos seres humanos de cerebro electrónico, que tratan a los ratones como príncipes. Decididamente, Pedro, en sus oscilaciones de la denigración a la exaltación de lo español, nos parece un típico representante de su país, agitado - según la lapidaria terminología 
de Américo Castro—entre las opuestas tendencias a "salir de sí" y a "retornar a sí". ${ }^{3}$

A ese íntimo nexo de lo individual y lo colectivo apunta el novelista en un pasaje muchas veces citado, donde, a los fines de mi interpretación, bastaría sustituir el término ciudad (aplicable a la capital de España) por el término país o patria: "De este modo podremos llegar a comprender que un hombre es la imagen de una ciudad y una ciudad las vísceras puestas al revés de un hombre, que un hombre encuentra en su ciudad no sólo su determinación como persona y su razón de ser, sino también los impedimentos múltiples y los obstáculos invencibles que le impiden llegar a ser" (p. 16). Siguen estas palabras a la magnífica descripción de Madrid, que figura al principio de la novela, y donde es muy visible el deseo de "salir de sí". Pues allí se escucha el lamento por la carencia de "una auténtica judería"y de "individuos auténticos de la raza nórdica" (p. 14), junto a la esperanza de que los habitantes de la ciudad "dejen vacías las grandes construcciones redondas o elípticas de cemento armado para recogerse en la intimidad estrecha de sus casas"(p. 15). La idea del español como desprovisto de intimidad, hombre de plaza, vociferante y extravertido, llega hasta Martín-Santos desde la generación del 98 y de los hijos del 98 . En este punto, la voz narrativa no sabemos de quién es. $\mathrm{El}$ autor y Pedro se identificarían en su condición común de intelectuales, herederos del legado o mensaje de sus mayores. Muy a propósito me parece, por ello, la aparición inmediata en el texto de la primera persona del plural: "Hasta que llegue ese día, con el juicio suspendido, nos limitaremos a penetrar en las oscuras tabernas donde asoma sobre las botellas una cabeza de toro disecado con los ojos de vidrio" (p. 15, subrayado mío). Etc., etc. Las imágenes taurinas-castizas - persiguen a aquellos mismos que expresaron el ansia de huir de las "grandes construcciones redondas de cemento armado". El "salir de sí" (es decir, de la colectividad hispánica) conduce al "retornar a sí", en parte fatal, en parte voluntario. Se comprende que el autor, aunque se burle de Pedro, no lo condene. Están espiritualmente demasiado próximos, y la lucidez crítica del primero no es tampoco ajena al segundo. De ahí que el desdoblamiento autor-personaje deje paso, en ocasiones, al desdoblamiento del personaje mismo, quien pronuncia sobre sí (excediéndose a veces) la condena que el autor no pronuncia. El mejor ejemplo de esta actitud es el monólogo de Pedro en la cárcel (pp. 175-180).

Pero la regla según la cual individuo y ciudad (o colectividad social) se vinculan estrechamente, tiene una gloriosa excepción en la novela. Esta excepción es Cervantes, a quien se evoca en un pasaje que, a diferencia del anterior, no ha sido-que yo sepa-suficientemente destacado por la crítica.

3 Véase el apartado "Inmovilidad e intra nquilidad", en La realidad histórica de España, (México: Porrúa, 1954), pp. 587-590. 
Ped ro pasea por el Madrid viejo, donde Cervantes vivió; el recuerdo de éste lo acucia: “¿Puede realmente—se pregunta—haber existido en semejante pueblo, en tal ciudad como ésta, en tales calles insignificantes y vulgares un hombre que tuviera esa visión de lo humano, esa creencia en la libertad, esa melancolía desengañada tan lejana de todo heroísmo como de toda exageración, de todo fanatismo como de toda certeza?"(p. 62). Cervantes ejemplifica la posibilidadcasi milagrosa-de liberarse de las circunstancias ambientales: el cáncer que, como una maldición de siglos, corroe a España. Su excelsa persona se ha zafado de los defectos tradicionales (exageración, fanatismo) de su país y su raza. Alejado de todo heroísmo, se convierte paradójicamente en el verdadero héroe de la novela, el modelo a seguir. Modelo-diríamos-accesible, si bien sorprendente, no como el mítico Cajal. No hay ninguna ironía aquí. Aunque sea Pedro quien reflexione, sus pensamientos sin duda son compartidos por el autor. Así se contesta a los interrogantes suscitados por la evocación de Cervantes: " no es un hombre que pueda comprenderse a partir de la existencia con la que fue hecho" (p. 62). El mayor escritor español no sería, por tanto, característicamente español. Anomalía a la que se añade otra: no sería tampoco Cervantes escritor por deseo sino por necesidad. Leemos: "Como el otro-el pintor caballero-fue siempre en contra de su oficio y hubiera querido quizás usar la pluma sólo para poner floripondiadas rúbricas al pie de letras de cambio contra bancas ginovesas" (p. 62).

Claro que esta necesidad de escribir no es únicamente la de ganarse el sustento, sino también-como luego se indica (p. 65) - la de derramar su propio cáncer sobre papeles blancos; o sea, la de evitar la contaminación por el cáncer. Lo que permite establecer un paralelo entre Cervantes y su criatura Don Quijote. Cervantes, hostigado por las circunstancias, escribe en definitiva para no enloquecer. Su latente locura exige ser proyectada en un ser imaginario. Pero, ¿es Don Quijote un loco o un individuo que se finge tal, para a su vez poder también vivir? Escribe Martín-Santos: "Lo que Cervantes está gritand o a voces es que su loco no estaba realmente loco, sino que hacía lo que hacía para poder reírse del cura y del barbero, ya que si se hubiera reído de ellos sin haberse mostrado previamente loco, no se lo habrían tolerado [...]. $\mathrm{Y}$ el loco, manifiesto como no-loco, hubiera tenido en lugar de jaula de palo, su buena camisa de fuerza de lino reforzado con panoplias y sus veintidós sesiones de electroshockterapia" (p. 63). Siendo psiquiatra, Martín-Santos debe saber lo que dice. Quien no se resigna a ser absorbido por el medio ambiente ha de buscar algún subterfugio (como el de ser loco o el de ser escritor) que le permita decir lo que piensa. La peor locura es aquella que, como condena social, le adjudican a uno los demás. Calificado de loco, el ser peligroso socialmente (o sentido como peligroso) se transforma con facilidad en víctima, a la que encerrar en la cárcel del manicomio. 
Pedro, por más que admire a Cervantes, no puede seguir su ejemplo. Al final del monólogo lo vemos sumirse en un café de literatos, que como un pulpo hace presa de él: "Ya está incorporado a una comunidad de la que, a pesar de todo, forma parte y de la que no podrá deshacerse con facilidad. Al entrar allí, la ciudad - con una de sus conciencias más agudas-de él ha tomado nota: existe" (p. 65). La conciencia de su existencia se da sólo en cuanto ser social y, por consiguiente, alienado. Si la ciudad - según se dice en el pasaje de la descripción de Madrid-, acogiénd olo a uno le impide perderse, también le impide encontrarse a sí mismo, en su intimidad. $O$, en palabras del novelista, le permite encontrarse "en la cárcel, en el orfelinato, en la comisaría, en el manicomio, en el quirófano de urgencia"(p. 17). Añadiríamos ahora: en el café de literatos. Pedro es, pues, incapaz de acceder a esa intimidad o libertad que desesperadamente busca. Los modelos negativos de su país son mucho más determinantes de su conducta que el ejemplo insólito de Cervantes (o de Velázquez, el "pintor caballero"). Cervantes, como Unamuno ya advirtió en términos próximos a los de Martín-Santos, “de puro español llegó a una como renuncia de su españolismo, llegó al espíritu universal, al hombre que duerme dentro de todos nosotros". ${ }^{4}$ Pedro, en cambio, no rebasa el nivel de lo castizo, aunque se rebele contra ello. En su misma rebelión, resulta justamente muy castizo. A diferencia de Cervantes, le persigue el afán de gloria, que se concreta en la figura del torero o del ganador del Nobel, recibiendo los aplausos del público. La asociación con el torero, como símbolo de machismo, volverá a aparecer en la escena de la desfloración de Dorita. Pese a su inseguridad y remordimientos (también muy castizos), Pedro manifiesta entonces el orgullo de quien ha cumplido una verdadera proeza (p. 98).

Ocupémonos ya del final de Tiempo de silencio. Pedro ha salido de la cárcel, adonde lo condujo su supuesta intervención en el aborto causante de la muerte de Florita. Acaba de reunirse con Dorita, a la que lleva a una verbena popular. Cartucho, antiguo novio de Florita, aparece, y se venga de Pedro-a quien cree el amante de Florita-matando a Dorita. He aquí el fin de la descripción: "Dorita caía al suelo llenándose de sangre poco a poco [...], él [Cartucho] se iba hacia fuera sin esperar siquiera a ver la cara que pondría él [Pedro] cuando volviera con su gran paquete de churros y se encontrara con que la venganza había sido ejecutada, que no hay plazo que no se cumpla ni deuda que no se pague"(p. 232). Esas últimas palabras--como se recordaráfiguran en El burlador de Sevilla (III, 932-933, ed. de A. Castro) y se incluyen posteriormente en el título de la obra de Zamora, No hay plazo que no se cumpla ni deuda que no se pague y convidado de piedra, nueva versión del

${ }^{4}$ En torno al casticismo, en Ensayos, $7^{\text {a }}$ ed. (Madrid: Aguilar, 1966), p. 36. 
tema donjuanesco. En este marco de resonancias literarias, Cartucho, el emisario de la muerte, actuaría como el Comendador. Pedro, consiguientemente, sería el Don Juan, tras haber sido el gozador o destructor de "virginidades tomadas al paso", como a sí mismo se dice en un pasaje de la novela (p. 98), o el "bárbaro" (p. 225), como lo llama la madre de Dorita.

Pero lo más notable es que la muerte no se abate sobre Pedro-Don Juan, sino sobre la mujer. De este modo Cartucho, más que al Comendador, se asimila al héroe calderoniano, dando muerte a Dorita ya que no puede dársela a su novia, Florita. Es, con todo, evidente el lazo que une a esos dos personajes del Siglo de Oro: Comendador y marido calderoniano son representantes del honor tradicional. La mujer es la víctima de esa sociedad masculina, regida por el principio del honor. El hecho de que, en Tiempo de silencio, el representante del honor sea un pícaro demostraría indirectamente-o retrospectivamente-la verdadera naturaleza del honor. No es que éste se haya degradado en nuestros días (siendo asumido por los que eran más ajenos a él), sino que tal vez fue siempre, en el fondo, la treta de un pícaro utilizada por un supuesto caballero. La treta de que el hombre se vale para sujetar a la mujer o para huir de ella, de su omnipresente amenaza. Señalemos a este respecto que, para Pedro, la muerte de Dorita es más una liberación que un castigo. En este sentido, Cartucho no sería el rival de Pedro, sino su doble. En la frase antes citada, es interesante que el pronombre repetido él se refiera, sin que ca mbie el antecedente, la primera vez a Cartucho y la segunda a Pedro: "él se iba hacia fuera sin esperar siquiera a ver la cara que pondría él cuando volviera".

Por eso, la reflexión de Pedro sobre la muerte, que precede inmediamente a la muerte de Dorita, resulta sospechosa. Pedro medita acerca de "la proximidad de la muerte que a todos nos ronda y de la que conocemos la calidad de gusano indetenible y de la que sentimos el berbiquí incesante horadándonos de parte a parte mientras que hacemos como que no lo oímos" (p. 229). Esa meditación, de claro abolengo existencialista, aunque aparentemente reveladora de la conciencia del hombre auténtico, nos suena a falsa. Pues si, en efecto, la muerte asoma en seguida su faz, su víctima ha sido ciudadosamente - no azarosamente -elegida. Es, de nuevo, la mujer, mientras el hombre, el responsable de esta fantasía, permanece a salvo. La fantaseada muerte no es la muerte propia, sino la del ser-la mujer-que más que nadie amenaza nuestra integridad. Recuérdese que Pedro-torero imaginario-vio a Dorita, la noche de su desfloración, como un toro: "el toro que no muere, que crece, crece, crece y que revienta y lo envuelve en toda su materia negra como un pulpo amoroso" (p. 98). La muerte (precisamente la del ser, Dorita, que se resistía a morir) es, por tanto, una manera de protegerse contra la propia muerte: la de Pedro, la del hombre. 
Al final de la novela, Pedro se nos aparece en la sima de su degradación. ${ }^{5} \mathrm{Ha}$ perdido no sólo a la mujer, sino también su empleo en el laboratorio, y se dispone a ir a un pueblecito castellano donde ejercerá la medicina. Noble actividad, sin duda, pero que da sólo pie a fantasías lamentables: "Podrás cazar perdices, podrás cazar perdices muy gordas cuando los sembrados estén ya... podrás jugar al ajedrez en el casino" (p. 239). Pedro recuerda al "hombre del casino provinciano", denostado por Antonio Machado en un célebre poema ${ }^{6}$ Las perdices, además, se confunden con mujeres en la imaginación del protagonista: "miraré las mozas castellanas, gruesas en las piernas como perdices cebadas y que, como ellas, pueden ser saboreadas con los dientes y con la boca o bien ser derribadas al suelo de un bastonazo" ( $p$. 237). Pedro es exponente del sadismo o violencia contra la mujer ejercido por la sociedad masculina.

Aquí querría recordar que Florita y Dorita, además de morir, son las dos objeto de una autopsia. Su cuerpo será abierto, sajado, manipulado. Así se convierten en verdaderas ratas, carne de vivisección a manos de los hombres. A su salida de Madrid, Pedro piensa en esto: “¿Qué querrán saber? Tanta autopsia; para qué, si no ven nada. No saben para qué las abren"(p. 234). Pese a la extrañeza manifestada, Pedro, en sus fantasías, participa de idéntico sadismo. Cierto, él también es una víctima, una rata más; pero su papel es cambiante: víctima y victimario a la vez. Incluso, en los cuidados que prodiga a Florita tras su aborto, advertimos la inutilidad de los mismos: Florita ha muerto ya. Pedro, impertérrito, se ensaña con un cuerpo muerto: "Un instinto [...] le decía que tales meticulosidades, tal hurgar cuidadoso con la cucharilla [...] carecía de toda utilidad. [...] La muerta no sufría y se dejaba con docilidad imponer unas maniobras que ya no tenían que ver con ella. [...] Pedro $[\ldots]$ continuaba automáticamente el raspado y una vez concluido, taponaba con la gasa limpia destinada a los ratones"(pp. 110-111). Junto a la oposición o falta de integración de las distintas clases sociales, expuesta en Tiempo de silencio (especialmente en la memorable descripción de la

${ }_{5}^{5}$ No creo que, en ese final, haya una toma de conciencia por parte de Pedro y, en relación con ello, una cura de tipo psicoanalítico, según afirman José Schraibman, "Notas sobre la novela española contemporánea", Revista Hispánica Moderna, 35(1969), 120; Schraibman, "Tiempo de silencio y la cura psiquiátrica de un pueblo: España", Insula, No. 365 (1977), p. 3; Felisa L. Heller, "Voz narrativa y protagonista en Tiempo de silencio", Anales de la novela de posguerra, 3(1978), 35-36 y passim. Para una opinión contraria: Robert Spires, La novela española de posguerra (Madrid: Cupsa, 1978), p. 199.

No obstante, Schraibman tiene razón al ver la novela como un intento de cura psiquiátrica de España. Esta interpretación fundamental ha sido Schraibman, que yo sepa, el primero en avanzarla, y me complace reconocer mi deuda con él a tal respecto.

6 "Del pasado efímero", Campos de Castilla, CXXXI. 
conferencia de Ortega, [pp. 130-133] la obra refleja también la oposición o guerra de los sexos. ${ }^{7}$

descripción de la conferencia de Ortega, [pp. 130-133] la obra refleja también la oposición o guerra de los sexos.?

El casticismo de Pedro culmina en su asimilación al mundo castellano, que inicialmente le era ajeno. Tras la violenta crítica del "reseco y carcomido, amojamado hombre de la meseta, [...] donde la idea de lo que es futuro se ha perdido hace tres siglos y medio" (p. 236), Pedro reconoce su incapacidad tanto de desligarse de ese mundo como de asumirlo profundamente: " ¿Desdichados de los que no servimos para el éxtasis! ¿Quién nos auxiliará? ¿Cómo haremos para penetrar en las más avanzadas y profundas de las Moradas donde nos es preciso habitar?" (pp. 236-237). Pedro es la víctima (mas no del todo inocente) de un sistema donde se exaltan los valores espirituales en detrimento de lo instintivo. La imposibilidad de vivir conforme a ese modelo (de inspiración castellana) conduce a una desintegración de la personalidad y, en definitiva, a una suerte de castración. ${ }^{8}$ Lo peor es que esa castración complace al protagonista: "Es cómodo ser eunuco, es tranquilo, estar desprovisto de testículos, es agradable a pesar de estar castrado tomar el aire y el sol mientras uno se amojama en silencio"(p. 238).

En fin, el clímax de la abyección de Pedro se alcanza en la última página del relato: "¿Y qué demonios puede importarle a nadie si yo soy ingenioso o no soy ingenioso o si era ingeniosa la puta que me parió?"(p. 240). La expresión se encuentra en el Quijote. El caballero andante, tras arremeter contra los cueros de vino, manifiesta su creencia de haber dado muerte a un gigante. A lo que Sancho replica: "el gigante muerto es un cuero horadado; y la sangre, seis arrobas de vino tinto que encerraba en su vientre; y la cabeza cortada es la puta que me parió, y llévelo todo Satanás" (I, xxxvii). Francisco Rodríguez Marín, en su edición del Quijote, comenta así este nasaje: "Lo mismo que Sancho aquí, dice en Rinconete y Cortadillo el sacristán a quien éste había hurtado la bolsa. [...] Allí noté (página 381 de mi edición crítica) algo que es

\footnotetext{
${ }^{7}$ Las observaciones sobre la conducta de Pedro ante Florita provienen de un trabajo inédito de Gisèle Feal. Para la dimensión sociológica de la novela, además de los estudios citados de Ortega y Curutchet, véase Félix Grande, "Luis Martín-Santos: Tiempo de silencio", Cuadernos Hispanoamericanos, No. 158 (1963), pp. 337-342; Pablo Gil Casado, La novela social española (1942-1968)(Barcelona: Seix Barral, 1968), pp. 274-290; Gonzalo Sobeja no, Novela española de nuestro tiempo, $2^{\mathrm{a}}$ ed.. (Madrid: Prensa Espa ñola, 1975), pp. 545-554; Alfonso Rey, Construcción y sentido de Tiempo de silencio (Madrid: José Porrúa Turanzas, 1977), pp. 184-201.

${ }^{8}$ John Caviglia ha mostrado muy bien cómo la falta de integración de la vida racional y la vida instintiva, ejemplificada por Pedro, equivale a la desconexión entre las clases altas y bajas de la sociedad. ("A Simple Question of Symmetry: Psyche as Structure in Tiempo de silencio", Hispania, 60 [1977], 452-460).
} 
aplicable a este lugar: 'En la frase del sacristán cervantino hay una reticencia, pues dice de su propia madre lo que, por la ira con que responde a la burlona pregunta de Rincón, se entiende que quiso decir de la madre de éste' ". 9 Pero en Pedro no se da tal reticencia, ya que no dialoga con nadie, sino que sinplemente monologa. Su aberrante declaración genealógica lo inserta, más bien, en el mund o de la picaresca, si no preferimos decir que remacha su figura de pícaro. ${ }^{10}$ La obnubilación es ahora total. Vemos en Pedro a un nuevo Lazarillo, a través de cuya bajeza Martín-Santos-como el autor del Lazarillo - expone la bajeza de un mundo falsamente revestido de nobles ideales. La actitud extremosa del protagonista impide, en efecto, toda posible identificación con él por parte del autor o del lector. Pero, justamente, esa inconsciencia de Pedro exige más que nunca la agudización de la conciencia del lector, que venga a suplir el clamoroso vacío. Sobre las ruinas del castizo anti-héroe, y tras el reconocimiento de sus taras (que forman también parte de nuestro bagaje), debe construirse otro mundo. Un mundo donde, como en el apuntado por Cervantes, pueda vivirse en paz y en libertad. $O$, en palabras de Martín-Santos, sacadas de uno de sus escritos científicos, con las que terminaré:

[...] el ser del hombre no está determinado por las condiciones exteriores, sino simplemente enajenado.

[...] A la enajenación caracteriza una cierta ignorancia de la coacción: la coacción no es vivida con plena conciencia a pesar de su realidad inexorable. Las contradicciones sufridas no son plenamente vividas hasta que se logra la operación fundamental de la toma de conciencia. Al ser vividas por un hombre, por un grupo, por un pueblo, éstos llegan a ser ejecutores de la historia y creadores de una nueva totalidad. "I

\footnotetext{
9 Don Quijote de la Mancha, ed. de Rodríguez Marín, (Madrid: Espasa-Calpe, 1962), III, 304.

10 Vicente Cabrera ha hablado de "la incongruencia entre lo que el personaje parece ser y lo que realmente prueba ser. Lo que parece ser inicialmente: un científico moderno, no concuerda con lo que el personaje hace a lo largo de su odisea". "Elaboración temática y técnica de Tiempo de silencio de Luis Martín-Santos", Sin Nombre, 3 (1973), 67.

11 "Dialéctica, totalización y concientización", en Apólogos (Barcelona: Seix Barral, 1970), p. 139.
} 
